-Review

\title{
Role of cortical spreading depression in the pathophysiology of migraine
}

\author{
Yilong Cui, Yosky Kataoka, Yasuyoshi Watanabe \\ Division of Bio-function Dynamics Imaging, RIKEN Center for Life Science Technologies, 6-7-3 Minatojima minamimachi, \\ Chuo-ku, Kobe, Hyogo 650-0047, Japan \\ Corresponding author: Yilong Cui. E-mail: cuiyl@riken.jp
}

(C) Shanghai Institutes for Biological Sciences, CAS and Springer-Verlag Berlin Heidelberg 2014

A migraine is a recurring neurological disorder characterized by unilateral, intense, and pulsatile headaches. In one-third of migraine patients, the attacks are preceded by a visual aura, such as a slowly-propagating scintillating scotoma. Migraine aura is thought to be a result of the neurovascular phenomenon of cortical spreading depression (SD), a self-propagating wave of depolarization that spreads across the cerebral cortex. Several animal experiments have demonstrated that cortical SD causes intracranial neurogenic inflammation around the meningeal blood vessels, such as plasma protein extravasation and pro-inflammatory peptide release. Cortical SD has also been reported to activate both peripheral and central trigeminal nociceptive pathways. Although several issues remain to be resolved, recent evidence suggests that cortical SD could be the initial trigger of intracranial neurogenic inflammation, which then contributes to migraine headaches via subsequent activation of trigeminal afferents.

Keywords: cortical spreading depression; migraine; neurogenic inflammation; PET; trigeminal nociceptive pathway

\section{Introduction}

Cortical spreading depression (SD), described first by Leao $^{[1]}$, is a self-propagating wave of transient neuronal/ glial membrane depolarization that is accompanied by a transient negative shift of the direct current (DC) potential ${ }^{[2]}$ and temporal elevation of cerebral blood flow $(\mathrm{CBF})^{[3,4]}$ throughout the cerebral hemisphere at a rate of $2-5 \mathrm{~mm} /$ $\min ^{[1,5,6]}$. The rate of spreading correlates with the observed spread of the aura of a classical migraine ${ }^{[7]}$, which is characterized by a spot of flickering light that appears near the center of the visual field and then gradually expands outward $^{[8-10]}$. Recently, cortical SD has been hypothesized to be the initial event involved in migraine headaches. Moskowitz et al. ${ }^{[11,12]}$ proposed that pro-inflammatory peptides, such as substance $P$ and calcitonin generelated peptide (CGRP), released from trigeminocervical nerve terminals in response to some unknown stimulation, probably cortical SD, induces vasodilation and plasma protein extravasation. Such neurogenic inflammation is thought to trigger a headache via stimulation of trigeminal afferents. Consistent with this hypothesis, cortical SD induced intracranial neurogenic inflammation around the meningeal blood vessels ${ }^{[13-15]}$, and subsequent activation of both peripheral ${ }^{[16]}$ and central ${ }^{[17]}$ trigeminal nociceptive pathways has been described. Here, we review the experimental evidence mainly from neurophysiological studies that has advanced the understanding of whether and how the neurovascular phenomenon of cortical SD causes intracranial neurogenic inflammation, and subsequently participates in triggering a migraine headache.

\section{Migraine Pathophysiology}

A migraine is a recurring neurological disorder characterized 
by unilateral, intense, and pulsatile headaches lasting $4-72 \mathrm{~h}^{[18]}$, and is often associated with symptoms including nausea, vomiting, and sensitivity to light, sound, or smel[ ${ }^{[19]}$. In one-third of migraine patients, the attack is preceded by transient neurological symptoms like sensory or motor deficits, collectively referred to as a migraine aura ${ }^{[9,20,21]}$. Most common is a visual aura, a scintillating scotoma, in which a spot of flickering light appears near the center of the visual field and then gradually expands outward ${ }^{[8-10]}$.

Several theories have been proposed to explain the pathophysiology of migraine: the vascular, neural, and trigeminovascular theories. In the 1930s, Harold Wolff ${ }^{[22]}$ and colleagues proposed the vascular theory, wherein the neurological symptoms of migraine aura are caused by cerebral vasoconstriction, and the migraine pain is evoked by vasodilatation of the extracranial terminal branches of the external carotid artery. They found that the intensity of migraine pain is closely related to the amplitude of pulsation in the occipital and superficial temporal branches of the external carotid arteries ${ }^{[22]}$. In the 1980s, Olesen and colleagues found the presence of spreading oligemia, a $20 \%-30 \%$ reduction of cerebral blood flow that appears first in the posterior part of the brain and then gradually spreads into the parietal and temporal lobes at a rate of 2-3 $\mathrm{mm} / \mathrm{min}$ during an episode of migraine with aura ${ }^{[8,23,24]}$. The spread of oligemia does not match the territories of the major cerebral arteries, but follows the cortical surface, implying a neural, rather than a vascular cause ${ }^{[23]}$. A highly variable increase in the cerebral blood flow is often followed by oligemia ${ }^{[25,26]}$, but the periods of increased cerebral blood flow do not correlate temporally with the experience of migraine headache ${ }^{[8,23,27]}$, suggesting that the intracranial vasodilation is likely an epiphenomenon, rather than a cause of the migraine headache.

In 1941, Karl Spencer Lashley ${ }^{[10]}$, a psychologist at Harvard University, described his own experience of a visual aura, where a scotoma started as a small area, then gradually enlarged, and spread toward the periphery of the visual field, and the propagation rate was estimated to be $3 \mathrm{~mm} / \mathrm{min}$ or less. Three years later, Aristides Leao ${ }^{[1]}$ reported the phenomenon of cortical SD, characterized by a self-propagating wave of depolarization that begins in the neuronal/glial cells of local areas of the brain and subsequently spreads in all directions at a rate of $\sim 3 \mathrm{~mm} /$ min. The similarity of Lashley's migraine aura and Leao's cortical SD was first picked up by Milner in $1958^{[7]}$, and further investigated by Olesen in the 1980s, as described above. Based on both Lashley's description of a spreading scotoma ${ }^{[10]}$ and Leao's findings of cortical SD ${ }^{[1]}$, the pathogenic theories changed from primary vascular to primary neural mechanisms.

In the 1980s, Moskowitz and colleagues reconciled the primary vascular and primary neural views and proposed the trigeminovascular theory ${ }^{[11,12]}$. They hypothesized that some unknown stimulation, probably the cortical $\mathrm{SD}$, depolarizes the trigeminocervical nerve terminals innervating the meninges, and pro-inflammatory peptides such as substance $P$ and CGRP are released from the primary meningeal afferents, which further induce vasodilation and plasma protein extravasation. Such neurogenic inflammatory reactions were thought to trigger headache via stimulation of the trigeminal afferents. Supporting this theory, plasma extravasation was observed during electrical stimulation of the trigeminal ganglion in the rat ${ }^{[11]}$, and pro-inflammatory peptides including CGRP and substance $P$ were released in response to electrical stimulation of the trigeminal ganglion in humans and cats $^{[28]}$. Moreover, the theory was supported by clinical studies where the CGRP levels were found to be increased in the jugular vein of patients during migraine attacks ${ }^{[29]}$, and vasogenic leakage from the leptomeningeal vessels has also been shown in at least one case of migraine with aura ${ }^{[30]}$, two cases of prolonged migraine aura and during spontaneous or familial hemiplegic migraine attacks ${ }^{[31,32]}$.

\section{Leao's Cortical Spreading Depression}

The mysterious phenomenon of cortical SD was first identified in the rabbit cerebral cortex by Aristides Leao, a young Brazilian neurophysiologist, during his Ph.D. fellowship in the Department of Physiology at Harvard University ${ }^{[1]}$. At that time, Leao was studying the electroencephalogram (EEG) of experimental epilepsy in the cerebral cortex of an anesthetized rabbit, but he was distracted by a contradictory and unexpected result that the EEG activity was silenced for a minute, and such suppression propagated slowly across the cerebral hemisphere. This phenomenon was then extensively studied around the world ${ }^{[33-36]}$, and has been characterized 
as a self-propagating wave of depolarization associated with a transient negative shift of the DC potential ${ }^{[2]}$ and temporal elevation of the $\mathrm{CBF}^{[3,4]}$. These changes in $\mathrm{DC}$ potential and CBF spread throughout the cortical gray matter at a rate of $\sim 3 \mathrm{~mm} / \mathrm{min}^{[1,5,6]}$.

Cortical SD can be evoked by tetanic electrical stimuli, mechanical stimuli such as pressure on or puncture of the cortex, alkaline $\mathrm{pH}$, low osmolarity, and chemical stimuli such as potassium ions or glutamate ${ }^{[36-38]}$. Recently, we demonstrated that transient tissue oxidation in a restricted local area of the rat cerebral cortex also induces cortical $\mathrm{SD}^{[3]}$. To restrict oxidation within a sub-millimeter region, we used a unique technique, photo-dynamic tissue oxidation (PDTO) technique, developed by Kataoka et al. for assessing the spatially- and temporally-controlled brain tissue oxidation from outside the brain within seconds or minutes $^{[39]}$. PDTO was carried out by application of rose Bengal, a photo-sensitizing dye, to a discrete region of the brain, followed by photo-irradiation through the dura mater. We found a high-amplitude DC potential shift ( 50 $\mathrm{mV}$ ) in the photo-oxidized area, and such a shift of the DC potential recovered gradually over the next $3 \mathrm{~h}$ (Fig. 1$)^{[3]}$. A series of DC potential negative shifts with an amplitude of approximately $-25 \mathrm{mV}$ was observed in the surrounding area, indicating that a representative cortical SD was induced by prolonged and synchronized membrane depolarization in the photo-irradiated area ${ }^{[3]}$.

The propagation of cortical SD is thought to involve the release and diffusion of some excitatory chemical mediators, most likely $\mathrm{K}^{+}$and glutamate, into the interstitial fluid $^{[40]}$. Mechanisms that modulate cortical excitability have been demonstrated to contribute to cortical SD propagation, such as the local distribution of astrocytes, which is known to stabilize the extracellular milieu ${ }^{[38,41]}$. Astrocytes have been reported to remove $\mathrm{K}^{+}$from the extracellular space by several mechanisms, including inwardly-rectifying $\mathrm{K}^{+}$channels, the $\mathrm{Na}^{+} / \mathrm{K}^{+}$-ATPase and $\mathrm{Na}^{+}-\mathrm{K}^{+}-\mathrm{Cl}^{-}$co-transporters, and spatial $\mathrm{K}^{+}$buffering via gap junctions ${ }^{[42,43]}$. Indeed, astrocytes have been reported to prevent the occurrence of SD through spatial buffering of the extracellular $\mathrm{K}^{+[44]}$. Moreover, several studies have reported that the spread of SD stops where white matter
A

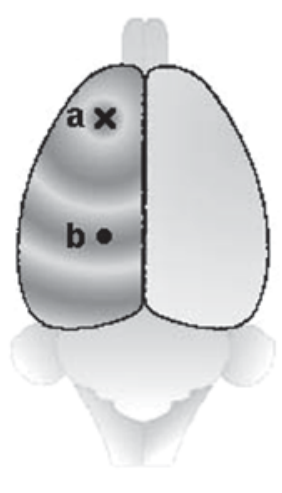

B

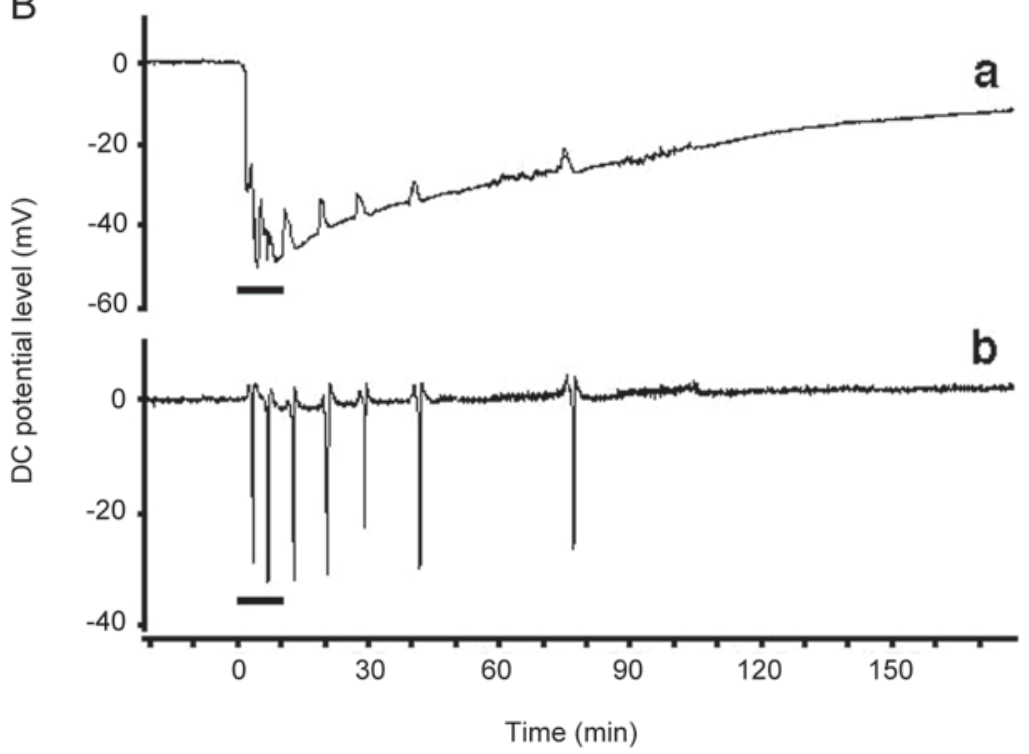

Fig. 1. A: Schematic of the experimental method (brain viewed from above). The rose Bengal was injected into the frontal cortex (point a, represented by a cross), and two microelectrodes were placed in both the dye-injected site (point a) and in the parietal cortex (point b). The dye-injected site (cross) was then photo-irradiated. B: DC potential changes recorded from the dye-injected site (a) and the surrounding area (b). The bars indicate photo-irradiation for $10 \mathrm{~min}$. Note the transient positive deflections in the upper panel, which are thought to be induced by local current passing between the recording site and the neighboring tissue undergoing depolarization (adapted from Cui et al. Biochem Biophys Res Commun $2003^{[3]}$ ). 
begins and at the edge of glial-fibrous scars left by previous injury or infarction ${ }^{[45,46]}$. Consistent with these observations, we also demonstrated that the velocity of cortical SD gradually decreases from the dorsal to the ventral cortical areas of the insular cortex, in which the volume distribution of astrocyte is known to gradually increase.

Recently, we have also demonstrated that the brain serotonergic system, which is known to modulate the excitability of cortical neurons through activation of several receptor subtypes, in particular, 5-HT1A, 5-HT2A, and 5 -HT3 receptors ${ }^{[47-49]}$, contributes to the propagation of cortical SD. Pyramidal neurons in the cerebral cortex express 5-HT1A and 5-HT2A receptors, which exert opposing effects on the excitability and firing activity of pyramidal neurons ${ }^{[47,49]}$. Activation of 5 -HT1A receptors hyperpolarizes, whereas activation of $5-\mathrm{HT} 2 \mathrm{~A}$ receptors depolarizes pyramidal neurons ${ }^{[77-49]}$. On the other hand, 5-HT2A receptors are expressed in large and 5-HT3 receptors in small GABAergic interneurons ${ }^{[50]}$. The activation of the excitatory receptors $5-\mathrm{HT} 2 \mathrm{~A}$ and $5-\mathrm{HT} 3$ in GABAergic interneurons directly excites GABAergic interneurons, and indirectly inhibits the firing of pyramidal neurons in the cortex and hippocampus ${ }^{[51,52]}$. Although the activation of 5-HT2A receptors in pyramidal neurons results in the activation of neurons, a preferential inhibitory action of $5-\mathrm{HT}$ has been reported in vivo ${ }^{[48]}$. Such a preferential inhibitory action of $5-\mathrm{HT}$ on cortical neurons could be explained by the different binding affinities of $5-\mathrm{HT}$ for $5-\mathrm{HT} 1 \mathrm{~A}$ and $5-\mathrm{HT} 2$ receptors. Hoyer et al. ${ }^{[53]}$ reported that $5-\mathrm{HT}$ has a much higher binding affinity for $5-\mathrm{HT} 1 \mathrm{~A}$ than 5 -HT2 receptors in the cerebral cortex. We also found that the propagation velocity of cortical SD is increased, possibly by extending the width of the depolarization wave, in neonatal rats treated with 5,7-dihydroxytryptamine $e^{[54]}$, in which the serotonergic innervation in the cerebral cortex is chronically decreased due to pharmacological degeneration of the dorsal raphe serotonergic neurons (Fig. 2). These results indicate that the excitability of the cerebral cortex might be increased by chronic dysfunction of serotonergic innervation in the cerebral cortex, and such a mechanism would explain the facilitation of migraine with a low serotonin disposition. Likewise, increased excitability of the cerebral cortex caused by gene mutation, such as missense mutation of CACNA1A (encoding the $\alpha_{1}$ subunit of neuronal Cav2.1(P/Q-type) calcium channels), a representative gene mutation in familial hemiplegic migraine (FHM) families, induces migraine susceptibility by lowering the threshold of cortical SD generation ${ }^{[55]}$.

\section{Cortical SD Induces Neurogenic Inflammation in}

\section{Rat Cerebral Cortex}

Cortical SD is thought to be a trigger of neurogenic inflammation around meningeal blood vessels, and then evokes headache pain via the activation of trigeminal afferents ${ }^{[11,12,56]}$. Bolay et al. ${ }^{[13]}$ demonstrated that cortical SD causes vasodilation of the middle meningeal artery and subsequent plasma protein leakage mediated by the release of pro-inflammatory peptides from trigeminal axon collaterals innervating the meninges. Further evidence ${ }^{[15]}$ supports the idea that a long-lasting (up to $48 \mathrm{~h}$ ) disruption of the blood-brain barrier can be induced by cortical SD, due to activation of the matrix metalloproteinase-9 (MMP9) cascade. The MMP-9 levels increase from 3 to $6 \mathrm{~h}$ after the induction of cortical SD in the ipsilateral cerebral hemisphere, reaching a maximum at $24 \mathrm{~h}$ and persisting for at least $48 h^{[15]}$. Plasma protein leakage and brain edema are also contemporaneous $3 \mathrm{~h}$ after cortical SD induction. These observations suggest that the plasma protein extravasation and pro-inflammatory peptides release from primary meningeal afferents might be a pivotal step in the cortical SD-induced neurogenic inflammatory process and subsequent headache. However, conflicts exist, as several drugs that selectively inhibit plasma protein extravasation in rodents have failed to reduce the pain severity in patients with migraine as evidenced by the failure in clinical trials of substance $P$ and neurokinin-1 antagonists ${ }^{[57]}$ and specific plasma protein extravasation blockers such as 4991 w93 $^{[58]}$ and $\mathrm{cp} 122,288^{[59]}$. Such contradictory evidence indicates that an appropriate method is necessary to investigate whether and how the neuroinflammation is involved in migraine etiology and to verify the extrapolated data from animal studies for the human condition.

Recent advances in non-invasive molecular imaging techniques, such as positron emission tomography (PET), provide powerful tools for quantitative investigation of the tissue distribution and dynamic changes of functional molecules in vivo, because of their high sensitivity and 

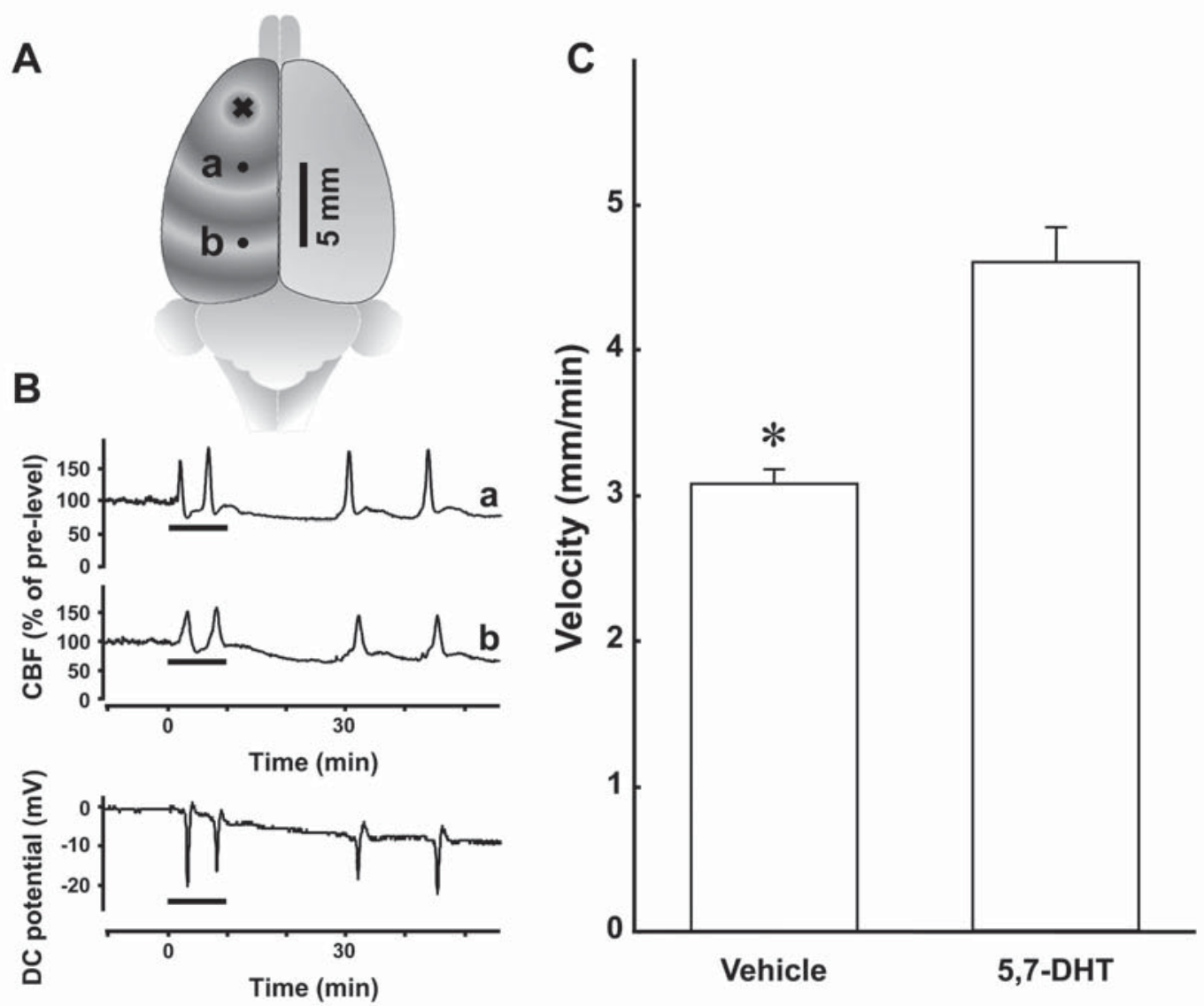

Fig. 2. Increased velocity of cortical SD in 5,7-dihydroxytryptamine (5,7-DHT)-treated rats. A: Schematic of the experimental method (brain viewed from above): two laser Doppler flow probes were placed on the same side as the dye-injection (cross) at different distances (point a, $4 \mathrm{~mm}$; point b, $9 \mathrm{~mm}$ ). A microelectrode was placed near the caudal probe (point b) for recording DC potential changes. B: PDTO-induced changes in cerebral blood flow (CBF, upper) and in the DC potential (lower). Bars indicate photo-irradiation for 10 min. C: Spreading velocity in 5,7-DHT-treated (65 hyperperfusions in eight animals) and vehicle-treated rats (51 hyperperfusions in six animals). ${ }^{*} P<0.05$, unpaired $t$-test (adapted from Cui et al. J Neurosci Res $2013^{[54]}$ ).

spatiotemporal resolution. PET imaging with specific probes designed for binding to inflammatory processes, such as $\left[{ }^{11} \mathrm{C}\right]$ PK11195, $\left[{ }^{11} \mathrm{C}\right] \mathrm{DAA} 1106,\left[{ }^{11} \mathrm{C}\right] \mathrm{DPA}-713$, and $\left[{ }^{11} \mathrm{C}\right] \mathrm{CLINME}$ have been widely used for studying brain inflammation ${ }^{[60-63]}$. The principal immune cells in the central nervous system, microglia, are activated in response to inflammatory processes in the brain ${ }^{[64]}$. The process of microglial activation is thought to be related to an increase in the number of microglia and the expression of numerous proteins such as the peripheral benzodiazepine receptor $(P B R)^{[65]}$. The PBR is a mitochondrial outer membrane protein, and is expressed at a low level on resting microglia and astrocytes in the normal brain. Its expression is upregulated in activated microglia ${ }^{[66-68]}$, and the upregulation is well correlated with the state of activation ${ }^{[69-71]}$. ${ }^{11} \mathrm{C}$-labeled PK11195 is a specific PET ligand for PBR to image activated microglia in the brain, and has been extensively used for quantitative evaluation of brain inflammation by PET in a number of neurological disorders, such as stroke ${ }^{[72]}$, multiple sclerosis ${ }^{[69]}$, Alzheimer disease $^{[73]}$, Parkinson disease $\mathrm{e}^{[74]}$ and Huntington disease ${ }^{[75]}$.

Using [ $\left.{ }^{11} \mathrm{C}\right] \mathrm{PK} 11195$-PET imaging in rats, we demonstrated that unilateral cortical SD induces neurogenic inflammation in the ipsilateral cerebral hemispher ${ }^{[14]}$. The highest $\left[{ }^{11} \mathrm{C}\right] \mathrm{PK} 11195$ radioactivity was seen in the initial area of the cortical SD (KCl-microinjected 
site), and moderate radioactivity was observed in the ipsilateral surrounding areas, but not in the corresponding contralateral areas. In sham control rats, however, a slight increase in $\left[{ }^{11} \mathrm{C}\right] \mathrm{PK} 11195$ radioactivity was seen primarily in the $\mathrm{NaCl}$-microinjected site. $\left[{ }^{11} \mathrm{C}\right] \mathrm{PK} 11195$ radioactivity is barely observed within the brain under normal conditions in control rats, except for the lateral, third, and fourth ventricles (Fig. 3). Our immunohistochemical study also confirmed that the number of OX-42-immunopositive microglia is increased in the ipsilateral hemisphere compared with the corresponding area in the contralateral hemisphere in rats with unilateral cortical SD (Fig. 4). Hypertrophied (enlarged, darkened soma with shorter, thicker processes) or amoeboid (densely stained, enlarged soma with a few short processes) OX-42-immunopositive microglia are often seen in the ipsilateral hemisphere. However, such a difference between the two hemispheres is not observed in sham-operated rats. These results indicate that cortical SD is able to induce microglial activation, a well-known sign of neuroinflammation in the brain.

\section{Cortical SD Activates the Trigeminal Nociceptive Pathway in the Rat Brain}

Migraine headaches are thought to be triggered by brain inflammation that activates trigeminal nociceptors in meningeal blood vessels ${ }^{[76]}$. However, it is still controversial whether the neurogenic inflammation induced by cortical
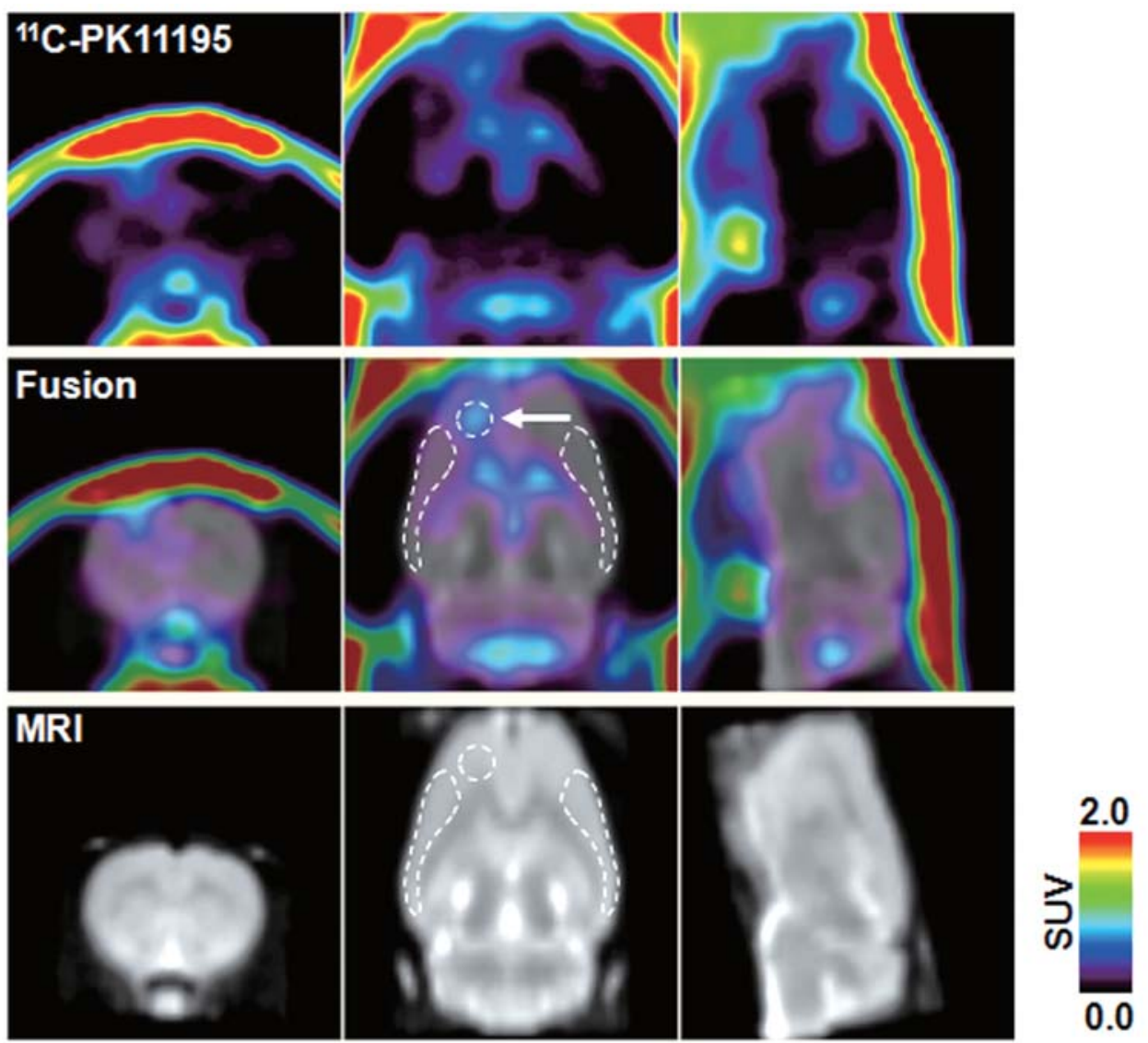

Fig. 3. A representative $\left[{ }^{11} \mathrm{C}\right] \mathrm{PK} 11195$ PET image co-registered with the MRI template eight days after generation of unilateral (left hemisphere) cortical SD. The PET image was reconstructed with the MAP algorithm and summed from 5 to 60 min after radioligand injection. The arrow in the middle panel indicates the $\mathrm{KCl}$-microinjected area. The white broken lines indicate the regions of interest (core, ipsilateral and contralateral). The mean values of binding potential for $\left[{ }^{11} \mathrm{C}\right] \mathrm{PK} 11195$ in the core and ipsilateral side were $0.48 \pm 0.18$ and $0.26 \pm 0.07$, respectively. Binding potential was estimated by Logan-noninvasive graphical analysis using contralateral as the reference region (adapted from Cui et al. J Nucl Med $2009^{[14]}$ ). 


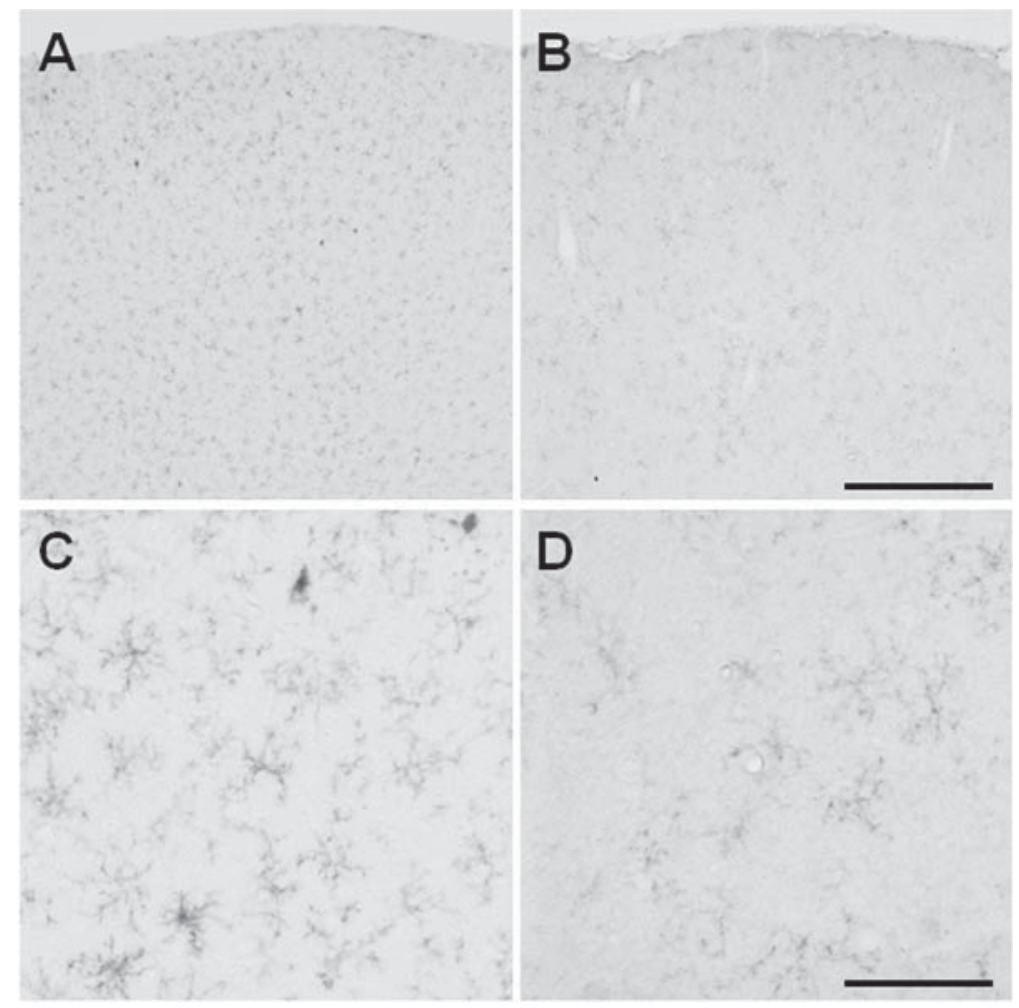

Fig. 4. Photomicrographs of OX-42 immunoreactivity following cortical SD. The images show the OX-42 immunoreactivity 8 days after $2 \mathrm{~h}$ of recurrent SD in the left hemisphere ( $A$ and $C$ ) compared with the contralateral hemisphere $(B$ and $D)$. C and $D$, magnified views of the OX-42 immunoreactivity. Hypertrophied or amoeboid OX-42-positive microglia were often seen in the left hemisphere. Scale bars, $500 \mu \mathrm{m}$ in A and B, and $100 \mu \mathrm{m}$ in C and D (adapted from Cui et al. J Nucl Med $2009^{[14]}$ ).

SD is able to activate the trigeminal nociceptive pathway. Recently, Moskowitz and colleagues demonstrated that C-Fos expression in the trigeminal nucleus caudalis (TNC), the first central site of the trigeminal nociceptive pathway, is significantly increased by cortical SD, and this increase is abolished by trigeminal rhizotomy ${ }^{[56]}$. Moreover, cortical SD-evoked single neuron activity in the trigeminal ganglion (peripheral pathway) and the TNC has also been demonstrated directly by electrophysiological studies ${ }^{[17]}$. Such activation was observed as a two-fold increase in $~ 50 \%$ of neurons in the trigeminal ganglion and TNC, and persisted for 45 min or longer. However, conflicting reports have shown that the cortical SD does not induce sustained neuronal activity recorded mainly in the deeper laminae of the more rostral trigeminal nucleus up to several hours after either a single or even a series of cortical SD inductions in the rat ${ }^{[77,78]}$.

We recently developed a small-animal neuroimaging method combining 2-[ ${ }^{18}$ F]fluoro-2-deoxy-D-glucose (FDG)
PET imaging with statistical parametric mapping analysis to evaluate the regional activity in the entire rat brain. Using the FDG-PET imaging method, we found that cortical SD activates the trigeminal nociceptive pathway, including both second-order and high-order nuclei, such as the thalamus and somatosensory cortex, $\sim 40 \mathrm{~h}$ after the induction of unilateral cortical SD (unpublished data). Consistently, several electrophysiological studies have reported that neurons in the high-order nuclei of the trigeminal nociceptive pathway are activated in response to inflammatory stimuli applied to the meninges ${ }^{[79,80]}$. A juxtacellular recording study has further revealed that the neurons located in the trigeminal thalamic areas (ventral posteromedial thalamic nucleus/ posterior thalamic nucleus) are activated by inflammatory stimulation of the meninges, and functionally project to diverse cortical areas, such as the trigeminal primary somatosensory (trigeminal barrel-field region of the primary somatosensory cortex, 
S1BF), trunk region of the primary somatosensory cortex, secondary somatosensory cortex, insula, primary visual cortex and primary auditory cortex ${ }^{[81]}$. Taken together, these observations suggest that cortical SD is able to activate the trigeminal nociceptive pathway and might contribute to migraine headache.

\section{Summary}

A migraine headache is a complex neurobiological disorder that has been hypothesized to be caused by intracranial neurogenic inflammation which activates trigeminal nociceptors in meningeal blood vessels. Since its discovery by Leao, cortical SD has been implicated in the pathophysiology of migraine due to the similar spreading velocity of cortical SD and the scintillating scotoma, a typical visual aura in migraine. Animal studies have demonstrated that cortical SD causes plasma protein extravasation around the meningeal blood vessels due to vasodilation of the middle meningeal artery or long-lasting disruption of the blood-brain barrier. Furthermore, direct and indirect evidence has shown that cortical SD activates both the peripheral (trigeminal ganglion) and the central pathways including the second-order and high-order nuclei of the trigeminal nociceptive pathways. These observations suggest that cortical SD is the initial trigger of prolonged neurogenic inflammation around the meningeal blood vessels, which probably evokes the headache sensation. Although the precise roles of cortical SD in migraine remain unclear, evidence from experimental models in rodents provides a valid platform for understanding the molecular mechanism of migraine and for promoting the development of new migraine therapies.

\section{ACKNOWLEDGMENTS}

This review was supported in part by a consignment expense from the Molecular Imaging Program on "Research Base for Exploring New Drugs" and by KAKENHI (24659574) from the Ministry of Education, Culture, Sports, Science, and Technology (MEXT) of the Government of Japan.

Received date: 2014-04-30; Accepted date: 2014-06-21

\section{REFERENCES}

[1] Leao AAP. Spreading depression of activity in the cerebral cortex. J Neurophysiol 1944, 7: 359-390.

[2] Nedergaard M, Hansen AJ. Spreading depression is not associated with neuronal injury in the normal brain. Brain Res 1988, 449: 395-398.

[3] Cui Y, Kataoka Y, Li QH, Yokoyama C, Yamagata A, Mochizuki-Oda $\mathrm{N}$, et al. Targeted tissue oxidation in the cerebral cortex induces local prolonged depolarization and cortical spreading depression in the rat brain. Biochem Biophys Res Commun 2003, 300: 631-636.

[4] Fabricius M, Akgoren N, Lauritzen M. Arginine nitric-oxide pathway and cerebrovascular regulation in cortical spreading depression. Am J Physiol 1995, 269: H23-H29.

[5] Hansen AJ, Zeuthen T. Extracellular ion concentrations during spreading depression and ischemia in the rat-brain cortex. Acta Physiol Scand 1981, 113: 437-445.

[6] Lauritzen M, Jorgensen MB, Diemer NH, Gjedde A, Hansen AJ. Persistent oligemia of rat cerebral-cortex in the wake of spreading depression. Ann Neurol 1982, 12: 469-474.

[7] Milner PM. Note on a possible correspondence between the scotomas of migraine and spreading depression of Leao. Electroencephalogr Clin Neurophysiol 1958, 10: 705-705.

[8] Lauritzen M. Pathophysiology of the migraine aura. The spreading depression theory. Brain 1994, 117: 199-210.

[9] Rasmussen BK, Olesen J. Migraine with aura and migraine without aura: an epidemiological study. Cephalalgia 1992, 12: 221-228; discussion 186

[10] Lashley KS. Patterns of cerebral integration indicated by the scotomas of migraine. Arch NeurPsych 1941, 46: 331-339.

[11] Markowitz S, Saito K, Moskowitz MA. Neurogenically mediated leakage of plasma protein occurs from blood vessels in dura mater but not brain. J Neurosci 1987, 7: 4129-4136.

[12] Moskowitz MA. The neurobiology of vascular head pain. Ann Neurol 1984, 16: 157-168.

[13] Bolay H, Reuter U, Dunn AK, Huang Z, Boas DA, Moskowitz $M A$. Intrinsic brain activity triggers trigeminal meningeal afferents in a migraine model. Nat Med 2002, 8: 136-142.

[14] Cui Y, Takashima T, Takashima-Hirano M, Wada Y, Shukuri M, Tamura $\mathrm{Y}$, et al. ${ }^{11} \mathrm{C}-\mathrm{PK} 11195 \mathrm{PET}$ for the in vivo evaluation of neuroinflammation in the rat brain after cortical spreading depression. J Nucl Med 2009, 50: 1904-1911.

[15] Gursoy-Ozdemir Y, Qiu J, Matsuoka N, Bolay H, Bermpohl $\mathrm{D}$, Jin $\mathrm{H}$, et al. Cortical spreading depression activates and upregulates MMP-9. J Clin Invest 2004, 113: 1447-1455.

[16] Zhang X, Levy D, Noseda R, Kainz V, Jakubowski M, Burstein R. Activation of meningeal nociceptors by cortical spreading depression: implications for migraine with aura. $\mathrm{J}$ Neurosci 2010, 30: 8807-8814.

[17] Zhang X, Levy D, Kainz V, Noseda R, Jakubowski M, Burstein R. Activation of central trigeminovascular neurons 
by cortical spreading depression. Ann Neurol 2011, 69: 855865.

[18] The International Classification of Headache Disorders: 2nd edition. Cephalalgia 2004, 24 Suppl 1: 9-160.

[19] Blau JN. Migraine: theories of pathogenesis. Lancet 1992 , 339: 1202-1207.

[20] Lipton RB, Scher Al, Kolodner K, Liberman J, Steiner TJ, Stewart WF. Migraine in the United States: epidemiology and patterns of health care use. Neurology 2002, 58: 885-894.

[21] Silberstein SD. Migraine. Lancet 2004, 363: 381-391.

[22] Graham JR, Wolff HG. Mechanism of migraine headache and action of ergotamine tartrate. Arch NeurPsych 1938, 39: 737-763.

[23] Olesen J, Larsen B, Lauritzen M. Focal hyperemia followed by spreading oligemia and impaired activation of Rcbf in classic migraine. Ann Neurol 1981, 9: 344-352.

[24] Woods RP, lacoboni M, Mazziotta JC. Brief report: bilateral spreading cerebral hypoperfusion during spontaneous migraine headache. N Engl J Med 1994, 331: 1689-1692.

[25] Lauritzen M. Cerebral blood flow in migraine and cortical spreading depression. Acta Neurol Scand Suppl 1987, 113: $1-40$.

[26] Andersen AR, Friberg L, Olsen TS, Olesen J. Delayed hyperemia following hypoperfusion in classic migraine. Single photon emission computed tomographic demonstration. Arch Neurol 1988, 45: 154-159.

[27] Olesen J, Friberg L, Olsen TS, Iversen HK, Lassen NA, Andersen AR, et al. Timing and topography of cerebral blood flow, aura, and headache during migraine attacks. Ann Neurol 1990, 28: 791-798.

[28] Goadsby PJ, Edvinsson L, Ekman R. Release of vasoactive peptides in the extracerebral circulation of humans and the cat during activation of the trigeminovascular system. Ann Neurol 1988, 23: 193-196.

[29] Goadsby PJ, Edvinsson L, Ekman R. Vasoactive peptide release in the extracerebral circulation of humans during migraine headache. Ann Neurol 1990, 28: 183-187.

[30] Arnold G, Reuter U, Kinze S, Wolf T, Einhaupl KM. Migraine with aura shows gadolinium enhancement which is reversed following prophylactic treatment. Cephalalgia 1998, 18: 644646.

[31] Lindner A, Reiners K, Toyka KV. Meningeal hyperperfusion visualized by MRI in a patient with visual hallucinations and migraine. Headache 1996, 36: 53-57.

[32] Smith M, Cros D, Sheen V. Hyperperfusion with vasogenic leakage by $\mathrm{FMRI}$ in migraine with prolonged aura. Neurology 2002, 58: 1308-1310.

[33] Gorji A. Spreading depression: a review of the clinical relevance. Brain Res Brain Res Rev 2001, 38: 33-60.

[34] Cui Y, Kataoka Y, Inui T, Mochizuki T, Onoe H, Matsumura K, et al. Up-regulated neuronal COX-2 expression after cortical spreading depression is involved in non-REM sleep induction in rats. J Neurosci Res 2008, 86: 929-936.

[35] Bures J, Buresova O, Krivanek J. The meaning and significance of Leao's spreading depression. An Acad Bras Cienc 1984, 56: 385-400.

[36] Somjen GG. Mechanisms of spreading depression and hypoxic spreading depression-like depolarization. Physiol Rev 2001, 81: 1065-1096.

[37] Guedes RC, do Carmo RJ. Influence of ionic disturbances produced by gastric washing on cortical spreading depression. Exp Brain Res 1980, 39: 341-349.

[38] Marshall WH. Spreading cortical depression of Leao. Physiol Rev 1959, 39: 239-279.

[39] Kataoka Y, Morii H, Imamura K, Cui Y, Kobayashi M, Watanabe $Y$. Control of neurotransmission, behaviour and development, by photo-dynamic manipulation of tissue redox state of brain targets. Eur J Neurosci 2000, 12: 4417-4423.

[40] Van Harreveld A. Two mechanisms for spreading depression in the chicken retina. J Neurobiol 1978, 9: 419-431.

[41] Leibowitz DH. The glial spike theory. I. On an active role of neuroglia in spreading depression and migraine. Proc Biol Sci 1992, 250: 287-295.

[42] Kofuji P, Newman EA. Potassium buffering in the central nervous system. Neuroscience 2004, 129: 1045-1056.

[43] Olsen ML, Sontheimer H. Functional implications for Kir4.1 channels in glial biology: from $\mathrm{K}^{+}$buffering to cell differentiation. J Neurochem 2008, 107: 589-601.

[44] Gardner-Medwin AR. Possible roles of vertebrate neuroglia in potassium dynamics, spreading depression and migraine. J Exp Biol 1981, 95: 111-127.

[45] Hull CD, Vanharreveld A. Absence of conduction of spreading depression through cortical region damaged by Asphyxiation. Am J Physiol 1964, 207: 921-924.

[46] Van Harreveld A, Terres G, Dernburg EA. Cortical discontinuity and propagation of spreading depression. Am J Physiol 1956, 184: 233-238.

[47] Araneda R, Andrade R. 5-Hydroxytryptamine2 and 5-hydroxytryptamine $1 \mathrm{~A}$ receptors mediate opposing responses on membrane excitability in rat association cortex. Neuroscience 1991, 40: 399-412.

[48] Puig MV, Artigas F, Celada P. Modulation of the activity of pyramidal neurons in rat prefrontal cortex by raphe stimulation in vivo: involvement of serotonin and GABA. Cereb Cortex 2005, 15: 1-14.

[49] Puig MV, Celada P, Diaz-Mataix L, Artigas F. In vivo modulation of the activity of pyramidal neurons in the rat medial prefrontal cortex by $5-\mathrm{HT} 2 \mathrm{~A}$ receptors: relationship to thalamocortical afferents. Cereb Cortex 2003, 13: 870-882.

[50] Jakab RL, Goldman-Rakic PS. Segregation of serotonin 
5-HT2A and 5-HT3 receptors in inhibitory circuits of the primate cerebral cortex. J Comp Neurol 2000, 417: 337-348.

[51] Kawa K. Distribution and functional properties of 5-HT3 receptors in the rat hippocampal dentate gyrus: a patchclamp study. J Neurophysiol 1994, 71: 1935-1947.

[52] Roerig B, Katz LC. Modulation of intrinsic circuits by serotonin 5-HT3 receptors in developing ferret visual cortex. J Neurosci 1997, 17: 8324-8338.

[53] Hoyer D, Engel G, Kalkman HO. Molecular pharmacology of 5-HT1 and 5-HT2 recognition sites in rat and pig brain membranes: radioligand binding studies with $[3 \mathrm{H}] 5-\mathrm{HT}$, $[3 \mathrm{H}] 8-$ OH-DPAT, (-)[125I]iodocyanopindolol, [3H]mesulergine and [3H]ketanserin. Eur J Pharmacol 1985, 118(1-2): 13-23.

[54] Cui Y, Li QH, Yamada H, Watanabe Y, Kataoka Y. Chronic degeneration of dorsal raphe serotonergic neurons modulates cortical spreading depression: a possible pathophysiology of migraine. J Neurosci Res 2013, 91: 737-744.

[55] van den Maagdenberg AM, Pietrobon D, Pizzorusso T, Kaja $\mathrm{S}$, Broos LA, Cesetti T, et al. A Cacna1a knockin migraine mouse model with increased susceptibility to cortical spreading depression. Neuron 2004, 41: 701-710.

[56] Moskowitz MA, Nozaki K, Kraig RP. Neocortical spreading depression provokes the expression of c-fos protein-like immunoreactivity within trigeminal nucleus caudalis via trigeminovascular mechanisms. J Neurosci 1993, 13: 11671177.

[57] Goldstein DJ, Wang O, Saper JR, Stoltz R, Silberstein SD, Mathew NT. Ineffectiveness of neurokinin-1 antagonist in acute migraine: a crossover study. Cephalalgia 1997, 17: 785-790.

[58] Earl NL, McDonald SA, Lowy MT. Efficacy and tolerability of the neurogenic inflammation inhibitor, 4991W93, in the acute treatment of migraine. Cephalalgia 1999, 19: 357-357.

[59] Roon KI, Olesen J, Diener HC, Ellis P, Hettiarachchi J, Poole $\mathrm{PH}$, et al. No acute antimigraine efficacy of CP-122,288, a highly potent inhibitor of neurogenic inflammation: Results of two randomized, double-blind, placebo controlled clinical trials. Ann Neurol 2000, 47: 238-241.

[60] Venneti S, Lopresti BJ, Wang G, Slagel SL, Mason NS, Mathis $\mathrm{CA}$, et al. A comparison of the high-affinity peripheral benzodiazepine receptor ligands DAA1106 and (R)-PK11195 in rat models of neuroinflammation: implications for PET imaging of microglial activation. J Neurochem 2007, 102: 2118-2131.

[61] Boutin H, Chauveau F, Thominiaux C, Kuhnast B, Gregoire $\mathrm{MC}$, Jan $\mathrm{S}$, et al. In vivo imaging of brain lesions with [(11)C]CLINME, a new PET radioligand of peripheral benzodiazepine receptors. Glia 2007, 55: 1459-1468.

[62] Boutin H, Chauveau F, Thominiaux C, Gregoire MC, James $\mathrm{ML}$, Trebossen R, et al. 11C-DPA-713: a novel peripheral benzodiazepine receptor PET ligand for in vivo imaging of neuroinflammation. J Nucl Med 2007, 48: 573-581.

[63] Banati RB. Visualising microglial activation in vivo. Glia 2002, 40: 206-217.

[64] Kreutzberg GW. Microglia: a sensor for pathological events in the CNS. Trends Neurosci 1996, 19: 312-318.

[65] Moran LB, Duke DC, Turkheimer FE, Banati RB, Graeber MB. Towards a transcriptome definition of microglial cells. Neurogenetics 2004, 5: 95-108.

[66] Benavides J, Guilloux F, Rufat P, Uzan A, Renault C, Dubroeucq $\mathrm{MC}$, et al. In vivo labelling in several rat tissues of 'peripheral type' benzodiazepine binding sites. Eur J Pharmacol 1984, 99: 1-7.

[67] Cagnin A, Gerhard A, Banati RB. In vivo imaging of neuroinflammation. Eur Neuropsychopharmacol 2002, 12: 581-586.

[68] Casellas P, Galiegue S, Basile AS. Peripheral benzodiazepine receptors and mitochondrial function. Neurochem Int 2002, 40: 475-486.

[69] Banati RB, Newcombe J, Gunn RN, Cagnin A, Turkheimer F, Heppner $F$, et al. The peripheral benzodiazepine binding site in the brain in multiple sclerosis: quantitative in vivo imaging of microglia as a measure of disease activity. Brain 2000, 123 ( Pt 11): 2321-2337.

[70] Stephenson DT, Schober DA, Smalstig EB, Mincy RE, Gehlert DR, Clemens JA. Peripheral benzodiazepine receptors are colocalized with activated microglia following transient global forebrain ischemia in the rat. $\mathrm{J}$ Neurosci 1995, 15: 5263-5274.

[71] Vowinckel E, Reutens D, Becher B, Verge G, Evans A, Owens T, et al. PK11195 binding to the peripheral benzodiazepine receptor as a marker of microglia activation in multiple sclerosis and experimental autoimmune encephalomyelitis. J Neurosci Res 1997, 50: 345-353.

[72] Price CJ, Wang D, Menon DK, Guadagno JV, Cleij M, Fryer T, et al. Intrinsic activated microglia map to the peri-infarct zone in the subacute phase of ischemic stroke. Stroke 2006, 37: 1749-1753.

[73] Cagnin A, Brooks DJ, Kennedy AM, Gunn RN, Myers R, Turkheimer FE, et al. In-vivo measurement of activated microglia in dementia. Lancet 2001, 358: 461-467.

[74] Gerhard A, Pavese N, Hotton G, Turkheimer F, Es M, Hammers A, et al. In vivo imaging of microglial activation with [11C](R)-PK11195 PET in idiopathic Parkinson's disease. Neurobiol Dis 2006, 21: 404-412.

[75] Pavese N, Gerhard A, Tai YF, Ho AK, Turkheimer F, Barker $\mathrm{RA}$, et al. Microglial activation correlates with severity in Huntington disease: a clinical and PET study. Neurology 2006, 66: 1638-1643.

[76] Ray BS, Wolff HG. Experimental studies on headache - Pain- 
sensitive structures of the head and their significance in headache. Arch Surg 1940, 41: 813-856.

[77] Ebersberger A, Schaible HG, Averbeck B, Richter F. Is there a correlation between spreading depression, neurogenic inflammation, and nociception that might cause migraine headache? Ann Neurol 2001, 49: 7-13.

[78] Lambert GA, Michalicek J, Storer RJ, Zagami AS. Effect of cortical spreading depression on activity of trigeminovascular sensory neurons. Cephalalgia 1999, 19: 631-638.

[79] Davis KD, Dostrovsky JO. Properties of feline thalamic neurons activated by stimulation of the middle meningeal artery and sagittal sinus. Brain Res 1988, 454: 89-100.

[80] Noseda R, Kainz V, Jakubowski M, Gooley JJ, Saper CB, Digre $\mathrm{K}$, et al. A neural mechanism for exacerbation of headache by light. Nat Neurosci 2010, 13: 239-245.

[81] Noseda R, Jakubowski M, Kainz V, Borsook D, Burstein R. Cortical projections of functionally identified thalamic trigeminovascular neurons: implications for migraine headache and its associated symptoms. J Neurosci 2011, 31: 14204-14217. 